\title{
Grupo de gestantes e casais grávidos: fortalecendo a humanização do parto e
}

\section{nascimento}

\author{
Group of pregnant and pregnant couples: strengthening the humanization of child birth and birth \\ Grupo de gestantes y parejas embarazadas: fortaleciendo la humanización del parto y nacimiento
}

Recebido: 30/09/2021 | Revisado: 09/10/2021 | Aceito: 17/10/2021 | Publicado: 19/10/2021

\author{
Margarete Maria de Lima \\ ORCID: https://orcid.org/0000-0003-2214-3072 \\ Universidade Federal de Santa Catarina, Brasi \\ E-mail:margarete.lima@ufsc.br \\ Cibele Gonçalves de Souza \\ ORCID: https://orcid.org/0000-0002-5718-095X \\ Universidade Federal de Santa Catarina, Brasil \\ E-mail: cibele.souzagoncalves@gmail.com \\ Luana Santos Souza \\ ORCID: https://orcid.org/0000-0003-4329-5876 \\ Universidade Federal de Santa Catarina, Brasil \\ E-mail: luanasantossouza7@gmail.com \\ Roberta Costa \\ ORCID: https://orcid.org/0000-0001-6816-2047 \\ Universidade Federal de Santa Catarina, Brasil \\ E-mail: roberta.costa@ufsc.br \\ Nágila Espíndola Aguiar \\ ORCID: https://orcid.org/0000-0003-1139-6218 \\ Universidade Federal de Santa Catarina, Brasil \\ E-mail: mailto.espindolanagi@gmail.com \\ Bianca Bertotti Sonaglio \\ ORCID: https://orcid.org/0000-0002-5806-4299 \\ Universidade Federal de Santa Catarina, Brasil \\ E-mail: biancabs.enfermagem@gmail.com
}

\begin{abstract}
Resumo
Objetivo: Identificar qual a contribuição de um grupo de gestantes e casais grávidos para consolidação do princípio de humanização do parto e nascimento, na percepção das mulheres e seus acompanhantes. Método: pesquisa qualitativa descritiva e exploratória. A coleta de dados foi realizada por meio de entrevistas no período de agosto de 2018 a março de 2019. A análise foi realizada qualitativamente, conforme a proposta operativa de Minayo. Resultados: As atividades de educação em saúde desenvolvidas no grupo contribuem para a promoção e proteção do parto como processo saudável e fisiológico, preparam a mulher para a tomada de decisões e fortalecem as mulheres para o parto possível. Considerações finais: O Grupo de Gestantes e casais grávidos tem contribuído para a humanização da assistência ao parto e nascimento, proporcionando uma experiência agradável para os participantes.
\end{abstract}

Palavras-chave: Gravidez; Política de saúde; Parto; Educação em saúde; Humanização da assistência.

\begin{abstract}
Objective: To identify the contribution of a group of pregnant women and pregnant couples to consolidate the principle of humanization of childbirth and birth, in the perception of women and their companions. Method: descriptive and exploratory qualitative research. Data collection was performed through interviews from August 2018 to March 2019. The analysis was carried out qualitatively, according to the operative proposal of Minayo. Results: The health education activities carried out in the group contribute to the promotion and protection of childbirth as a healthy and physiological process, prepare women for decision making and empower women for possible childbirth. Final considerations: The Group of Pregnant Women and pregnant couples has contributed to the humanization of childbirth and birth care, providing a pleasant experience for the participants.
\end{abstract}

Keywords: Pregnancy; Health policy; Parturition; Health education; Humanization of assistance.

\section{Resumen}

Objetivo: Saber cual la contribución de un grupo de mujeres gestantes y parejas embarazadas para la consolidación del principio de la humanización del parto y nacimiento, en la percepción de las mujeres y sus acompañantes. Método: investigación cualitativa, descriptiva y exploratoria. La cola de datos se realizó mediante entrevistas desde agosto de 
2018 hasta marzo de 2019. El análisis se realizó cualitativamente, de acuerdo con la propuesta operativa de Minayo. Resultados: Las actividades de educación en la salud desarrolladas en el grupo contribuyen para la promoción y protección del parto como un proceso saludable y fisiológico, preparan la mujer para la tomada de decisión y las fortalecen las mujeres para el parto posible. Consideraciones finales: El grupo de mujeres gestantes y parejas embarazadas tiene contribuido para la humanización de la asistencia en el parto y nacimiento, proporcionando una experiencia agradable para los participantes.

Palabras clave: Embarazo; Política de salud; Parto; Educación en salud; Humanización de la atención.

\section{Introdução}

O processo de gestação e nascimento são eventos marcantes na vida das mulheres. Este momento singular e único que envolve o companheiro, família e comunidade é permeado por expectativas em relação à chegada do novo integrante da família e por sentimentos, como medo, ansiedade e inseguranças (Dodou et al., 2017). Essa experiência única para a mulher e sua família, necessita de atendimento qualificado, baseado nos princípios da humanização e integralidade do cuidado em saúde (Nunes \& Monte-mor, 2019).

A humanização no contexto da assistência obstétrica envolve um conjunto de conhecimentos, práticas, atitudes e posturas, pautadas no diálogo, acolhimento e empatia. Essa política pública de saúde tem impacto direto nos indicadores obstétricos, preconizando as boas práticas na atenção ao parto e nascimento, garantindo cuidados baseados em evidências, com abolição de práticas intervencionistas, respeito à privacidade e a autonomia da mulher durante a gestação, parto, nascimento e puerpério (Barros et al., 2018; Possati et al., 2017).

A Organização Mundial de Saúde (OMS) tem recomendado que a atuação de profissionais de saúde qualificados vá além das consultas de pré-natal, ou seja, estendam-se a atividades educativas desenvolvidas em grupos de gestantes, buscando promover a troca de conhecimento e o apoio à gestante. Neste sentido, os grupos devem funcionar como auxiliadores do prénatal e não substitutivos (Organização Mundial da Saúde, 2016).

Esses grupos contribuem para uma assistência pré-natal mais completa, pois a partir dos assuntos abordados e da troca de experiências é possível proporcionar à gestante novos conhecimentos - que muitas vezes não são plenamente trabalhados nas consultas - propiciando a interação entre participantes e profissionais (Malumbres \& Barreto, 2016). As ações educativas contribuem para estimular o protagonismo da mulher no cenário obstétrico e para a efetivação de garantia dos seus direitos preconizados nas políticas públicas de saúde (Reis et al., 2017). Promovem o fortalecimento das potencialidades individuais e coletivas, estimulam o exercício da cidadania, diminuem a ansiedade e contribuem para que as gestantes tenham informações sobre a humanização da assistência ao parto e nascimento (Zirr et al., 2019).

Apesar destes benefícios, ainda não são uma realidade para muitas mulheres e famílias, seja por pouca oferta em serviços de saúde, seja por desinteresse das gestantes. Neste sentido, conhecer a percepção dos participantes de grupos de gestantes acerca das contribuições desta atividade, pode estimular os profissionais de saúde a ofertar mais atividades educativas nesta perspectiva e incentivar uma maior procura das mulheres e seus acompanhantes por este tipo de serviço.

Diante do exposto, este estudo tem por objetivo identificar de que modo um grupo de gestantes e casais grávidos tem contribuído para a consolidação do princípio de humanização do parto e nascimento, na percepção das mulheres e seus acompanhantes.

\section{Metodologia}

Pesquisa qualitativa, descritiva e exploratória (Minayo, 2014). Realizado em um Grupo de Gestantes e Casais Grávidos de uma Universidade Pública do Sul do Brasil. Este grupo é uma atividade de extensão universitária, criada em 1996 com o objetivo de desenvolver atividade educativa e interdisciplinar para casais grávidos e gestantes do $4^{\circ}$ ao $8^{\circ}$ mês de gravidez. Tem 
como eixos norteadores os princípios preconizados nas políticas públicas de atenção à saúde da mulher, como a humanização da assistência ao parto e nascimento. Anualmente são atendidas em média 100 gestantes, cada participante preenche uma ficha de inscrição, uma ficha de avaliação e participam do reencontro de pais e bebês que ocorre aproximadamente um mês após os nascimentos de todos os bebês de determinado grupo (Zirr et al., 2019; Lima et al., 2020).

A coleta foi realizada de agosto de 2018 a março de 2019 por meio de entrevistas individuais realizadas durante o reencontro de pais e bebês do Grupo Gestantes e Casais grávidos. Foram incluídas na coleta de dados as fichas de inscrição das participantes e de avaliação das atividades.

Como critérios de inclusão, foram estabelecidos, ser maior de 18 anos e ter participado do oitavo encontro do grupo de gestantes e do reencontro de pais e bebês.

As fichas de inscrição das mulheres continham informações referentes à identificação, gestação e participação em grupo de gestantes. As fichas de avaliação foram preenchidas pelas mulheres e seus acompanhantes no último encontro do grupo de gestantes, com informações referentes à avaliação das atividades desenvolvidas e à contribuição do grupo para a tomada de decisão no contexto da gravidez, do parto e puerpério. Para complementar as informações dos relatos, as fichas de avaliação foram lidas para buscar informações que abordassem a contribuição do grupo para a humanização do parto e nascimento.

Os dados coletados foram sistematicamente organizados, descritos, analisados concomitantes à coleta e interpretados na perspectiva de Minayo (Minayo, 2014), de acordo com os seguintes passos: ordenação dos dados, classificação dos dados e análise final. Tais passos foram guiados pelas recomendações atuais sobre a humanização do parto e nascimento (Word Health Organization, 2018; Brasil, 2017).

Respeitando os aspectos éticos foi preservado o anonimato neste estudo, os relatos foram identificados com a letra P de participantes e pela letra A de acompanhante, seguidos pelo número da ordem dos relatos e das fichas de avaliação. Sendo denominados de "P1 a P31 e A1 a A6". O presente estudo é integrante de um macroprojeto intitulado "20 anos do grupo de gestantes e casais grávidos: trajetória histórica, perfil, impacto, percepções e contribuições para os envolvidos”, aprovado no Comitê de Ética em Pesquisa sob n. 2.051.643.

\section{Resultados}

Todas as mulheres do grupo realizaram o pré-natal, em rede privada ou pública. Em sua maioria possuíam entre 26 e 39 anos e estavam em sua primeira gestação; mais da metade possuía acompanhante durante os encontros.

A partir da análise dos dados, os resultados foram descritos em quatro categorias que representam princípios da humanização do parto e nascimento preconizados pelo Ministério da Saúde brasileiro: "proteção e promoção do parto como processo saudável e fisiológico"; "Participação da mulher na tomada de decisões"; "fortalecendo as mulheres para o parto possível" e "grupo de gestantes como um espaço de educação em saúde".

Proteção e promoção do parto como processo saudável e fisiológico

A gestação é um processo natural em que a mulher vivencia experiências até então desconhecidas, ainda que não seja a primeira gestação. A partir das trocas de informações no grupo de gestantes e casais grávidos, os participantes relataram que conseguiram lembrar do que foi dito no grupo em relação ao parto como um processo natural e fisiológico.

"A gente conversa muito sobre os momentos que a gente teve aqui em grupo, e a L. [gestante] mesmo diz, desde lá ela ficou uma tarde e uma noite toda em trabalho de parto, para tentar o parto normal, se não fosse o suporte que a gente teve aqui ela não ia ter essa coragem..." (A6) 
“... a opção pelo parto normal (se possível) já era um fato, mas agora depois do curso, estamos muito mais seguros da nossa escolha e felizes pela rede de apoio que encontramos neste grupo.” (P19)

“...foi a parte mais maravilhosa do meu parto, eu fiz tudo que eu tinha planejado... era o meu momento de conexão com a minha filha...” (P13)

“...o grupo ajudou bastante, eu fiquei mais de 12 horas em trabalho de parto então eu tentei várias coisas que eu aprendi aqui..." (P14)

Os participantes enfatizaram o uso de técnicas não farmacológicas para alívio da dor, aprendidas nos encontros do grupo.

“...O parto foi ótimo, no parto eu lembrei de tudo, até (...) da respiração e ele me puxava, lembra que ela falava [referindo-se a uma das profissionais do grupo], você tem que respirar, você falou que ela falou, então tens que respirar..."(P4)

“...eu comecei a entrar em trabalho de parto às nove da noite, dai eu saí para caminhar, fiz tudo o que a gente aprendeu aqui, as massagens, caminhada, agachar, ficar de quatro, tudo isso...” (P15)

“...na hora que eu tava com contração meu marido fez as técnicas da massagem ... e as massagens realmente auxiliam na hora da dor assim, porque era muita dor.” (P16)

“Colocava água quente nas costas, na ducha, a melhor coisa. Eu só botava nas costas, porque lembro que aqui falaram de não botar na frente, que isso gerava falsas contrações.” (P18)

\section{Participação da mulher na tomada de decisões}

A assistência centrada na mulher prioriza seu bem-estar e participação nas decisões a serem tomadas durante o processo gravídico-puerperal, especialmente durante o parto e nascimento. A participação nas decisões foi encontrada nos relatos dos participantes:

"Me sinto empoderada, muito bem informada." (P9)

“Me sinto segura das minhas decisões e sem medo para enfrentar esse momento novo da minha vida.” (P8)

“...aqui foram passadas muitas posições e eu fiquei de quatro o tempo inteiro, porque foi a posição que eu conseguia...

Consegui me sustentar nessa posição em todo trabalho de parto praticamente. Eu me lembrava das coisas faladas no curso e pensava que legal, como foi importante...” (P3)

“...o grupo foi muito importante no trabalho de parto, na questão de respirar e se comunicar com o bebê, principalmente aquela coisa... de não ouvir o médico e fazer força, fazer força na hora que tu sentisses que era preciso e isso foi muito bom...” (P2)

“Me permitiu tomar decisões baseadas em informações científicas e atualizadas... ajuda a gente muito nisso, esse empoderar enquanto mulher, gestante, eu quero ter a minha autonomia, eu quero decidir pelo o meu corpo e pelo meu filho né..." (P6)

“...chegou um momento que eles falaram se eu queria ocitocina e eu falei que não, não queria ocitocina...” (P13)

"O parto ocorreu tudo conforme eu estipulei no plano de parto. Pedi o mínimo possível de interferências da própria enfermaria do hospital, e todos foram muito respeitosos." (P21) 
"E como a gente participou do processo do grupo, leu bastante, teve bastante informação, o B. [acompanhante] também, a gente viu bastante documentário... Teve até uma hora que na hora do expulsivo o médico tocou na cabeça do Z. [bebê] para dar uma puxada e o B. [acompanhante] falou “não toca, não mexe, não precisa!” (P22)

\section{Fortalecendo as mulheres para o parto possível}

Esta categoria diz respeito ao fortalecimento da mulher para a mudança de planos referente ao tipo de parto desejado e ao tipo de parto realizado. A primeira opção das mulheres foi o parto normal, contudo, não foi realizado por diferentes justificativas, conforme relatos apresentados:

“...e o parto em si, não foi exatamente do jeito que eu planejava, do jeito que a gente queria... e poderia ter mudança de planos que não estavam, que saíam do meu alcance ali. E foi o que aconteceu... ele estava com a cabecinha defletida, então na hora assim que veio a notícia: ah ele está e vai ter que ir para a cesárea ... para muita gente a cesárea vira uma questão, nossa para mim não foi, era a solução ali e tudo bem... mesmo na cesárea eu falo que parece que foi uma cesárea humanizada, porque a equipe ali da cesárea também foi muito atenciosa comigo...” (P5)

“...eu ganhei a L [bebê] de cesárea porque teve que ser cesárea, mas eu fui até 7 de dilatação, e assim eu lembrava sempre para não ficar desesperada, estava sendo de uma forma bem natural, é tipo, ia ser o parto normal né? o parto natural, só que aconteceu que dai ela fez mecônio e não evoluiu a dilatação e ela também não estava encaixada..." (P12)

“... "ok", vamos tentar a ocitocina, porque eu prefiro parto normal com ocitocina que cesárea e ai tomei a ocitocina e não evolui, não evoluiu e a médica veio falar comigo que teve parada de progressão, porque a G. [bebê] estava com a face para frente... eu queria muito que ela nascesse de parto normal, tipo eu me esforcei muito, en aguentei muito... eu aceitei e ok, foi o que a gente falou e eu lembrei muito do grupo nesse momento e falei "ok" né, é para minha filha e a minha filha é o mais importante, vou." (P13)

"Ai ele falou "olha acho que a gente precisa pensar em indicação de fazer uma cesariana ... tu estás bem, o R. [bebê] está muito bem, mas tens o edema que pode ser perigoso e a gente não quer que vocês fiquem em risco.". Eu falei "claro que sim", eu sempre quis muito parto normal, mas...não passei de dois centímetros e o edema eu sentia." (P23)

\section{Grupo de gestantes como um espaço para educação em saúde}

O grupo de gestantes como um espaço para educação em saúde e, em razão disso, fortalecedor da humanização, é evidenciado nas falas das participantes, quando elas relatam conseguir, a partir das experiências vivenciadas no grupo, ficar mais tranquilas durante o trabalho de parto e parto, lembrando das orientações fornecidas nas atividades e centrando a atenção do parto para elas mesmas.

“...acho que em todo momento a gente conseguiu tirar o melhor aqui do grupo, das experiências que a gente teve aqui, até mesmo para tranquilizar a gente porque é como se a gente tivesse contato com outras mães, já estava ali na nossa raiz e tranquilizando a gente né...” (P1)

“...como ela participou do grupo e tudo mais ela se sentiu segura, gostou da visita na maternidade e a gente se sentiu super seguro..." (A5) 
"O grupo foi muito importante, porque muitas coisas que a gente viu no grupo na hora que a gente está vivenciando a gente lembra, e já está um pouco mais preparada.” (P24)

“...foi de suma importância a participação neste grupo, pois me possibilitou a troca de experiências, um suporte emocional, bem como possibilitou reflexões importantes a partir de conhecimentos sobre questões fisiológicas e emocionais.” (P25)

"Ainda que eu já tenha tido uma experiência de parto, os ensinamentos do curso foram muito importantes para eu compreender muito do que vivi no primeiro para melhorar a “performance” no próximo.” (P26)

"Foi um espaço de bastante troca de experiências, o que me deixou mais segura em relação à gestação e à maternidade. Aprendi muito! Vou levar muitas informações valiosas.” (P29)

"Participar deste grupo teve grande importância no sentido de acolhimento e compartilhamento das nossas inseguranças/dúvidas. Além de proporcionar um maior empoderamento, mais confortável em encarar os diferentes períodos a base de informações necessárias para essa nova fase.” (P30)

\section{Discussão}

A primeira categoria deste estudo reforça as atuais recomendações da OMS e das diretrizes para a assistência ao parto normal (Word Health Organization, 2018; Brasil, 2017), que consideram o parto como um evento natural e fisiológico. Nesta perspectiva, é possível perceber, através dos relatos, que as orientações dadas no grupo estimularam as mulheres a vivenciá-lo de maneira mais positiva, por meio do controle da respiração, bastante destacado durante os encontros do grupo e por ter sido uma conduta fortemente utilizada para o alívio da dor durante o parto.

A dor presente durante o trabalho de parto e o parto, é vivenciada por cada mulher de maneira diferente. Nesse processo, estão envoltos hormônios e neurotransmissores, mas também o estado emocional da parturiente e o ambiente em que ela está (Lehugeur et al., 2017). Recursos não medicamentosos para alívio da dor, como técnicas de respiração e relaxamento, além de terem baixo custo, não são invasivos e são fáceis de aplicar, trazendo benefícios e contribuindo para o alívio da dor e diminuição da ansiedade, por exemplo, sem causar nenhum tipo de trauma para a parturiente e o feto, além de serem práticas vinculadas à humanização do parto (Possati et al., 2017; Lehugeur et al., 2017).

Um parto humanizado inclui o respeito à mulher e suas decisões, tal como foi exposto na segunda categoria deste estudo, notabilizando que a autonomia da mulher na tomada de decisões foi consequência, além do fortalecimento por parte dos profissionais e da rede de apoio, da procura por informações não só no grupo de gestantes, como também em outros meios de busca. A escolha da posição no momento do nascimento demonstra respeito à mulher e suas decisões, 14 evidenciando que as necessidades de cuidado são valorizadas (Malumbres \& Barreto, 2016)

No que diz respeito à terceira categoria, foi possível identificar nos relatos que embora tenha ocorrido a tentativa de evoluir para o parto normal, em determinado momento, as mulheres foram encaminhadas para a cesariana e essa mudança passou a percepção de ser bem aceita pela mulher. Reconhecer os elementos determinantes no processo de tomada de decisão sobre a via de parto é uma prática essencial para um nascimento saudável, sendo imprescindível que os profissionais envolvidos reconheçam o protagonismo da mulher nas tomadas de decisões no ciclo gravídico e puerperal (Arik, 2019).

Quando há uma situação de risco para a mulher ou para o bebê, a utilização de recursos tecnológicos (tecnologias leveduras e duras) é importante, já que proporciona segurança e traz benefícios, entretanto, não devem sobressair-se às tecnologias leves (que consistem em cuidar, apoiar e dar atenção a mulher). A incidência das tecnologias leve e leve-dura reduz o risco de morbimortalidade materna e neonatal. A operação cesariana, é necessária para alguns desfechos desfavoráveis durante o trabalho de parto. No entanto, não se deve justificar a realização de procedimentos invasivos e desnecessários apenas por ser uma conduta 
"mais segura" (Possati et al., 2017; Souza et al., 2019).

As mulheres na maioria das vezes não são informadas de forma clara sobre as reais indicações de operação cesariana. Para que a assistência ao parto e nascimento seja pautada na humanização é primordial que haja atuação conjunta da equipe de saúde evitando intervenções desnecessárias, diminuindo as taxas de cesarianas e consequentemente aumentando a satisfação materna. Destaca-se que a tomada de decisão e escolha da via de parto está diretamente relacionada ao recebimento de informações fornecidas às gestantes, às parturientes e suas famílias, à atuação da equipe multiprofissional e ao modelo de assistência obstétrica (Viana et al., 2018).

$\mathrm{Na}$ categoria referente ao grupo de gestantes como um espaço para educação em saúde, foi possível perceber a contribuição do grupo para o fortalecimento da autonomia e o empoderamento das mulheres e seus acompanhantes durante o parto. De acordo com os relatos, muitas questões abordadas durante os encontros foram lembradas e colocadas em prática, contribuindo para uma experiência agradável e sem danos.

Em estudo feito em uma casa de parto, foi evidenciado que grupos educativos realizados concomitantes ao pré-natal auxiliaram as mulheres a decidir sobre quais tecnologias não invasivas gostariam de utilizar em seu trabalho de parto, reforçando a necessidade de um pré-natal que proporcione autonomia no processo de parturição da mulher (Loiola et al., 2019).

Os grupos de gestantes complementam o atendimento pré-natal, já que este pode não suprir todas as demandas das gestantes nas consultas. Os assuntos abordados no grupo são questões importantes relacionadas a todo o período gravídicopuerperal.6 Além disso, preparam a mulher e seu acompanhante para o momento do parto e contribuem para uma melhor compreensão das mulheres sobre os benefícios do parto normal e sobre as corretas indicações da cesariana. Sabe-se, ainda, que esses grupos ajudam a diminuir o medo e a ansiedade na hora do parto, por proporcionarem conhecimento sobre esta fase e sobre seu próprio corpo, além de capacitá-las a participar das decisões e desenvolver sua autonomia (Matos et al., 2017; Lima et al., 2020).

\section{Considerações Finais}

O grupo de gestantes e casais grávidos é um espaço de educação em saúde, que contribui para a consolidação do princípio de humanização do parto e nascimento. A troca de informações entre mulheres e profissionais de saúde nas atividades educativas estimulam a vivência do parto como um processo fisiológico, seguro e centrado na mulher.

Como limitação destaca-se ser uma pesquisa local, em um grupo específico, cujos dados não podem ser generalizados. Sugerese que novos estudos possam ser desenvolvidos em unidades de saúde, maternidades e em outros grupos de gestantes, abordando os princípios da humanização na gestação e no período pós-parto.

\section{Referências}

Andrade, L. O., Felix, E. S. P., Souza, F. S., Gomes, L. O. S. \& Boery, R. N. S. O. (2017). Práticas dos profissionais de enfermagem diante do parto humanizado. Rev enferm UFPE, 6(11):2576-85. 10.5205/reuol.9799-86079-1-RV.1106sup201712.

Arik, R. M., et al. (2019). Perceptions and expectations of pregnant women about the type of birth. Revista Brasileira de Enfermagem, 72(3):41-49. https://doi.org/10.1590/0034-7167-2017-0731.

Barros, T. C. X., Castro, T. M., Rodrigues, D. P., Moreira, P. G. S., Soares, E. S. \& Viana, A. P. S. 1. (2018). Assistance to women for the humanization of chidlbirth and birth. Rev enferm UFPE, 12(2):554-8, https://doi.org/10.5205/1981-8963-v12i2a25368p554-558-2018.

Brasil (2017). Diretrizes Nacionais de Assistência ao Parto Normal: versão resumida. [Internet], Ministério da saúde. Disponível em: https://bvsms.saude.gov.br/bvs/publicacoes/diretrizes_nacionais_assistencia_parto_normal.pdf

Dodou, H. D., Rodrigues, D. P. \& Oriá, M. O. B. (2017). O cuidado à mulher no contexto da maternidade: caminhos e desafios para a humanização. Rev Fund Care Online. 9(1):222-30. http://dx.doi.org/10.9789/2175-5361.2017.v9i1.222-230. 
Lehugeur, D., Strapasson, M. R. \& Fronza, E. (2017). Manejo não farmacológico de alívio da dor em partos assistidos por enfermeira obstétrica. Rev enferm UFPE 11(12):4929-4937. https://doi.org/10.5205/1981-8963-v11i12a22487p4929-4937-2017

Lima, M. M., Dutra, S., Estácio, J. R., Costa, R., Roque, A. T. F. \& Maia, C. C. (2020). Contribuições de um grupo de gestantes e casais grávidos para seus participantes. Cogitare enferm. 25:e-66280. http://dx.doi.org/10.5380/ce.v25i0.66280.

Loiola, A. M. R., Alves, V. H., Vieira, B. D. G., Rodrigues, D. P., Souza, K. V., Marchiori, G. R. S., et al. (2019). A importância dos grupos educativos do prénatal na construção do plano de parto. Rev Norte Mineira de enferm. 8(1): 30-39. https://www.periodicos.unimontes.br/index.php/renome/article/view/2239/2297.

Malumbres, P. C. \& Barreto, I. C. H. C. (2016). Grupo de Gestantes: O relato de uma experiência. Enfermagem Revista 19(1): 47-63. http://periodicos.pucminas.br/index.php/enfermagemrevista/article/viewFile/11635/10312.

Matos, G. C., Demori, C. C., Escobal, A. P. L., Soares, M. C., Meincke, S. M. K. \& Gonçalves, K. D. (2017). Grupos de gestantes: espaço para humanização do parto e nascimento. Rev Fund Care 9(2):393-400. https://doi.org/10.9789/2175-5361.2017.v9i2.393-400.

Minayo, M. C. S. (2014). O desafio do conhecimento: pesquisa qualitativa em saúde. (14a ed.), Hucitec, 407.

Nunes, K. R. \& Monte-mor, D. S. (2019). Percepção das mulheres sobre a qualidade da assistência de enfermagem durante o parto. RGSS 8(2):111-125. 10.5585/RGSS.v8i2.14920

Organização Mundial de Saúde (2016). Recomendações da OMS sobre cuidados pré-natais para uma experiência positiva na gravidez. https://apps.who.int/iris/bitstream/handle/10665/250800/WHO-RHR-16.12-por.pdf;jsessionid=B23E5DF1CA6853E738ED80132EF1C7CD?sequence=2.

Possati, A. B., Prates, L. A., Cremonese, L., Scarton, J., Alves, C. N. \& Ressel, L. B. (2017). Humanização do parto: significados e percepções de enfermeiras. Esc. Anna Nery 21(4): e-20160366. https://doi.org/10.1590/2177-9465-EAN-2016-0366.

Reis, T. L. R., Padoin, S. M. M., Toebe, T. R. P., Paula, C. C. \& Quadros, J. S. (2017). Autonomia feminina no processo de parto e nascimento: revisão integrativa da literatura. Rev. Gaúcha Enferm 38(1): e-64677. https://doi.org/10.1590/1983-1447.2017.01.64677.

Souza, F. M. L. C., Santos, W. N., Santos, R. S. C., Rodrigues, O. B., Santiago, J. C. D. \& Silva, R. A. R. (2019). Tecnologias apropriadas ao processo do trabalho de parto humanizado. Enferm Foco 10(2):11=8-124. https://doi.org/10.21675/2357-707X.2019.v10.n2.2180.

Viana, T. G. F., Martins, E. F., Sousa, A. M. M., Souza, K. V., Rezende, E. M. \& Matozinhos, F. P. (2018). Motivo da realização de cesárea segundo relato das mães e registros de prontuários em maternidades de Belo Horizonte. Rev Min Enferm 22:e-1073. 10.5935/1415-2762.20180003

World Health Organization (2018). WHO recommendations: intrapartum care for a positive childbirth experience. https://www.who.int/reproductive health/publications/intrapartum-care-guidelines/en/.

Zirr, G. M., Petters-gregório, V. R., Lima, M. M. \& Collaço, V. S. (2019). Women's autonomy in child labor: contributions from a group of pregnant women. Rev Min Enferm. 23:e-1205. 10.5935/1415-2762.20190053 